\title{
Accuracy of the Cutler-Hammer Recording Gas Calo- rimeter When Used With Gases of High Heating Value
}

\author{
John H. Eiseman and Elwin A. Potter ${ }^{1}$
}

\begin{abstract}
The accuracy of the Cutler-Hammer recording gas calorimeter, when used with gases oí high heating value, is discussed. The study includes the preparation of a standard gas of high heating value, a comparison of hydrogen and methane as calibrating gases, the effect upon the instrument of changes in room and tank-water temperature, the instrument's accuracy when burning propane, the effects of bleeder burner height, and the effects of differences in inlet gas pressure. It is concluded that an accuracy of 0.25 percent, or even better, can be obtained with the Cutler-Hammer calorimeter if certain precautions are carefully followed.
\end{abstract}

\section{Introduction}

The tremendous increase in the distribution and use of natural gas during the past few years and the change from a cubic foot to the therm, or heating value, basis for the marketing of much of this fuel have caused many gas utility companies concern regarding the accuracy of the methods used for determining heating value.

At present, there are two general methods for determining the heating value of fuel gases. The first, and older, is by means of the manually operated water-flow calorimeter. This type of calorimeter was investigated in considerable detail at the Bureau by Waidner and Mueller $[1]^{2}$ some 40 years ago, and their publication is still a valuable reference work. A method of test for calorific value of gaseous fuels by the water-flow calorimeter has been adopted by the American Society for Testing Materials [2], and by this method an accuracy within plus or minus 0.5 percent can be obtained on gases of constant heating value. However, natural gas as delivered to consumers does not usually maintain a constant heating value and may vary over a wide range from day to day or even from hour to hour.

With a water-flow calorimeter, a trained operator requires approximately $30 \mathrm{~min}$ for a determination of heating value. Operation at this rate around the clock would reflect approximately 2 min of sampling time every $30 \mathrm{~min}$ and would leave the heating value unknown for about 94 percent of the time. Consequently, a calorimeter giving an automatic continuous record is finding more and more favor. At the present time, the only instrument of this kind on the market in this country is the Cutler-Hammer recording gas calorimeter, formerly known as the Thomas recording gas calorimeter.

The Cutler-Hammer calorimeter has received wide acceptance in the gas industry. However, in the past most of its use has been with manufactured gases of low heating value. A number of studies of the accuracy of this instrument on gases ranging from 500 to $700 \mathrm{Btu} / \mathrm{cu} \mathrm{ft}$ have been made, among which is one by R. S. Jessup [3] of the Bureau.

1 Mechanical Engineer, Gas Inspection Bureau of the District of Columbia.

Figures in brackets indicate the literature references at the end of this paper.
These studies have indicated that an accuracy well within 1 percent can be obtained, provided the calorimeter is given the necessary care, and provided also that the heating value of the gas does not vary too rapidly. Today the majority of the fuel gases used in the United States are of natural origin (predominantly methane) and have heating values that are higher and more varied than those used in the previous studies.

Because of the importance of this fundamental measurement to the gas-using public and to the gas industry, the Chemical Committee and the Promotion, Advertising, and Research Committee of the American Gas Association requested the National Bureau of Standards to undertake a study of the accuracy of the Cutler-Hammer recording gas calorimeter for testing gases of high heating value.

The Cutler-Hammer instrument has been designed to measure the total heating value of the usual commercial fuel gases. It is adapted to the use of a particular gas by making simple changes in the recorder scale and in the tank unit's gear train, orifice sizes, etc. The principle upon which the instrument operates is as follows: Gas is burned at a constant rate, and the heat developed is absorbed by a stream of air. The rates of flow of the gas, air for combustion, and air for the absorbing of heat are regulated by metering devices similar in design to the ordinary wet-gas meter. These metering devices are geared together and driven by an electric motor, so that the ratios of the rates of flow of gas, combustion air, and heat-absorbing air are constant. The gas meter is subject to independent change with respect to the tank water level in order to compensate for the wear of meter bearings and the accumulation of deposits inside the meters. The products of combustion are kept separate from the heat-absorbing air and are cooled very nearly to the initial temperature of the air. The water formed in the combustion is condensed to the liquid state. The rise in temperature of the heat-absorbing air is therefore proportional to the total heating value of the gas. This rise in temperature is measured by means of resistance thermometers of nickel and recorded graphically.

The meters are mounted in a tank of water, 
adjacent to a storage compartment of smaller capacity containing a reserve supply of water. A camoperated water pump takes water from the waterstorage compartment and delivers it into the main tank, where the excess flows over a weir and returns to the reserve compartment. Thus the water level in the main tank is automatically kept constant.

A schematic diagram of the calorimeter is shown in figure 1, which was taken from the book of instructions for the care and operation of the Cutler- attached to the outside of the burner chamber to promote heat transfer. The heat liberated in the combustion is nearly all absorbed by the heatabsorbing air, so that the products of combustion are cooled very nearly to the initial temperature of the air. The water formed in the combustion is condensed to the liquid state and drops into the condensate pan. To reduce heat loss the burner assembly is surrounded by a double-walled, nickelplated jacket, between the walls of which the

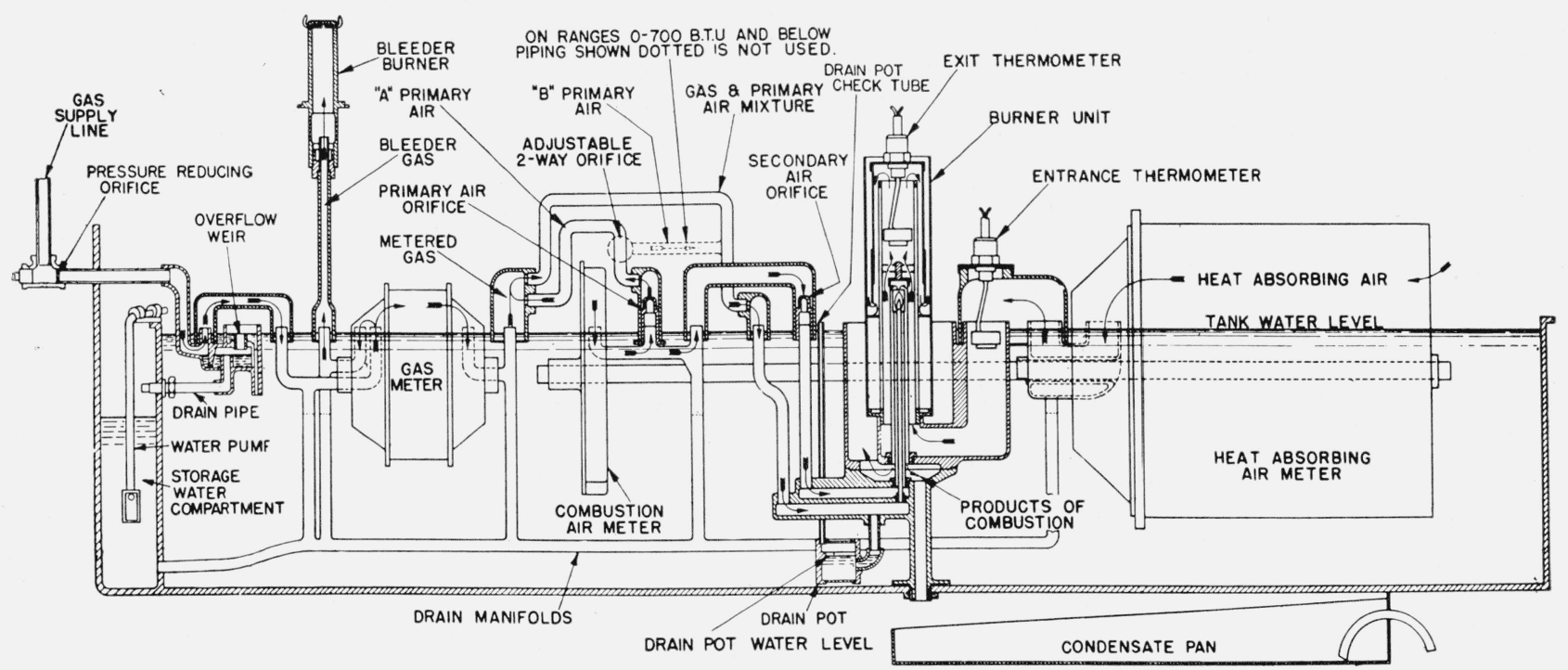

Figure 1. Flow diagram of the Cutler-Hammer recording gas calorimeter.

Hammer calorimeter [4]. Gas flows from the gas supply line through a pressure regulator and a pressure reducing orifice to the inlet chamber of the gas meter from which a part of it, approximately 85 percent, escapes through a bleeder burner and the remaining 15 percent is taken up by the gas meter. The design of this part of the calorimeter is such that the resistance to flow of gas from the inlet chamber of the gas meter to the bleeder burner is small, so that the pressure in the chamber will be nearly the same as that of the atmosphere. Practically, the differential does increase somewhat as the inlet pressure of gas to the calorimeter is increased. After leaving the gas meter the gas is mixed with air from the combustionair meter, and this mixture then flows to the calorimeter burner. Figure 2 is a schematic diagram of the burner unit.

The air from the combustion-air meter is caused by appropriate orifices to divide into three streams, two of primary air (A and B, fig. 1), which enter the gas stream at two points between the gas meter and burner, and a third, which flows up around the burner tube and constitutes a supply of secondary air for combustion. The burner is located in a chamber that is closed at the top and open at the bottom, so that the products of combustion rising from the burner are deflected and caused to flow downward. The heat-absorbing air flows upward around the burner chamber past a system of fins

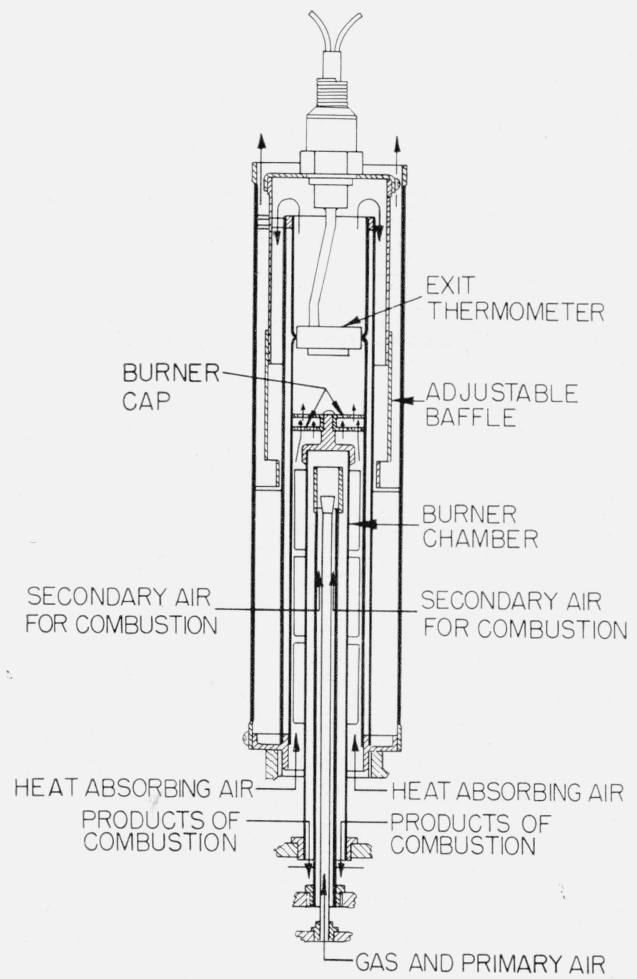

FIgure 2. Schematic diagram of burner unit and jacket. 
heat-absorbing air flows after passing the outlet thermometer (the inlet thermometer being in the same stream of air before it reaches the burner assembly). The distance of the flow of this air between the walls of the jacket is regulated by a baffle (fig. 2) that can be adjusted to effect an increase or decrease in the temperature rise of the heatabsorbing air and thus accomplish the desired reading of the instrument to coincide with the heating value in Btu per cubic foot of the gas used for calibration.

The temperature rise of the heat-absorbing air is measured by nickel resistance thermometers connected in adjacent arms of a Wheatstone bridge, which, with a specially calibrated slide-wire resistance $\mathrm{S}$, is the measuring circuit of a Leeds \& Northrup recorder. A diagram of this circuit is shown in figure $3 .^{3}$ The equal ratio arms of the bridge are

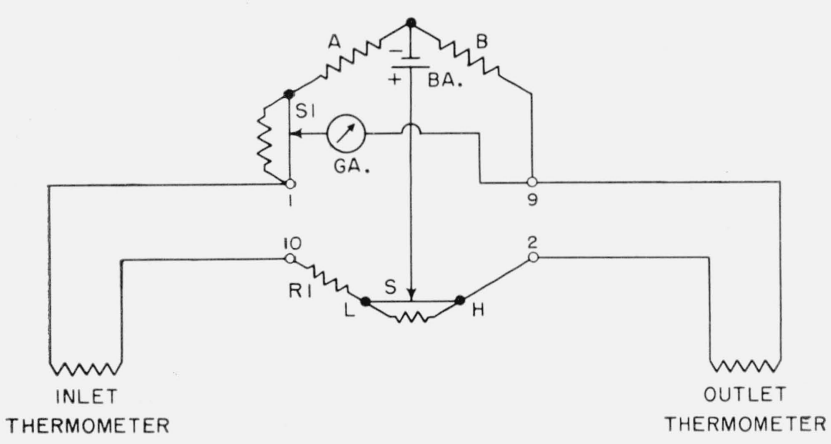

FIGURE 3. Wiring diagram of recording system.

shown at $A$ and $B$. The adjustable resistance, $S_{1}$, is used to balance the bridge during the "cold-balance" adjustment of the recorder when the thermometers are theoretically at the same temperature. A rectifier furnishes current for the system. Any lack of balance in the bridge causes a galvanometer needle to deflect, and this actuates the recording mechanism, which moves a contact along slide-wire resistance $\mathrm{S}$ so as to bring the bridge back into balance. The position of this sliding contact is a direct indication of the temperature difference between the two thermometers and is recorded by means of a pen on a motor-driven paper roll, which is graduated in Btu per cubic foot, and which also accounts for time.

Some of the factors that affect the accuracy of the calorimeter to a greater or lesser degree include changes in the temperature of the water in the tank, the kind and nature of the gas used for calibration, the degree of saturation of the gas sample (see appendix A), the inlet gas pressure, the bleeder burner height, the degree of permanence of the level of the water surrounding the meters (see appendix B), and the amount of free play in meter bearings and recorder parts, etc.

The data obtained in this paper show that errors resulting from such effects may be considerably larger than might be expected from the precision

${ }^{3}$ An explanation of the identifying letters or numerals shown on figure 3 , but not referred to in this paper, will be found in the Cutler-Hammer Instruction Manual [4]. attained in calibration of the calorimeter. A knowledge of the effect of such factors is essential to keeping the over-all error of measurement to a minimum.

In planning this work the theory behind the design of the calorimeter was carefully examined, but as an analysis of the theory had been published in a previous Bureau paper it was felt that only brief reference to such theory was required in this study. It was decided that the investigation should be concerned mostly with the functional accuracy of the instrument when operating under normal or field conditions. In order to save time, some of the field conditions were artificially created.

The authors conducted all of the tests made during this study under carefully controlled conditions of temperature. Most of the tests were made at the National Bureau of Standards, but some were repeated in the temperature controlled laboratory of the District of Columbia Gas Inspection Bureau, and some in the testing room at the Cutler-Hammer factory.

At the Bureau, the area containing the calorimeter and all accessory equipment was suitably enclosed and thermostatically controlled air-conditioning equipment was installed, by means of which any room temperature between $50^{\circ}$ and $100^{\circ} \mathrm{F}$ could be maintained within $\pm 1 \mathrm{deg} F$. The relative humidity in the enclosure was controlled by means of a humidistat. Figures 4 and 5 show two views of this air-conditioned enclosure.

Devices were also installed to permit the maintenance of any desired temperature of the water in the calorimeter independently of room temperature. In the tank unit, temperatures above that of the room were maintained by conduction of heat from the auxiliary tank as its water was heated by submerged copper coils through which hot water was circulated from a thermostatically controlled source adjacent to the tank unit. Temperatures below that of the room were maintained by conduction of heat from the main tank to the auxiliary tank as its water was cooled by circulating cold water through the same

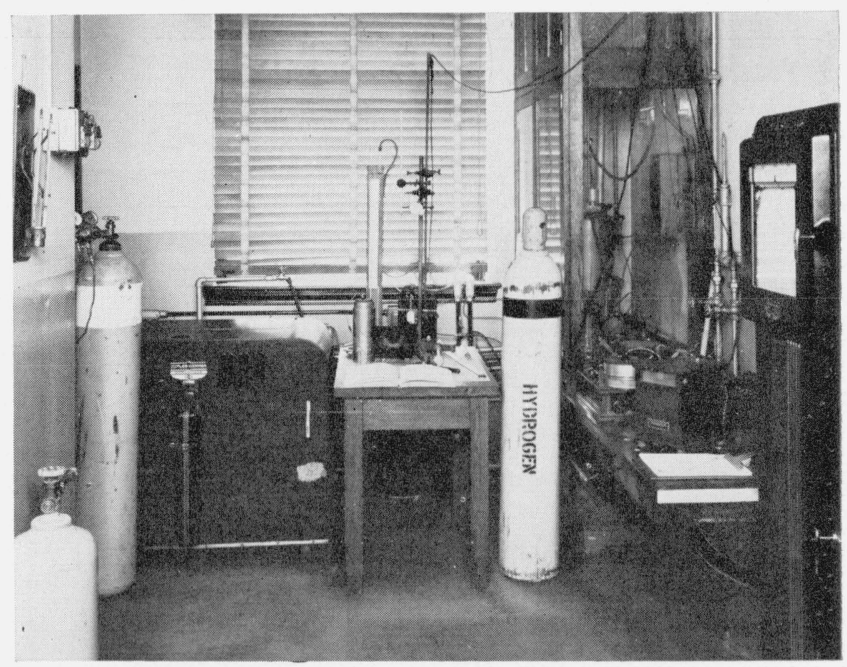

Figure 4. Air-conditioned calorimeter room. 


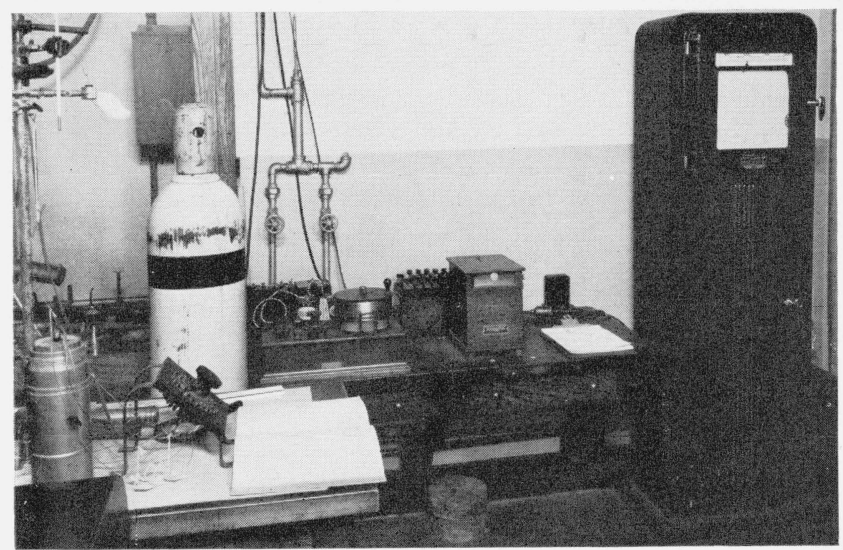

Figure 5. Air-conditioned calorimeter room.

submerged coils. Such changes in water temperature were effected slowly, in order that they might be accomplished uniformly. As a result, simultaneous temperature measurements at different locations in the tank unit showed no differences.

Measurements of existing temperatures were determined at appropriate locations by means of copper-constantan thermocouples, accompanied in some instances by accurate mercurial thermometers graduated in tenths of degrees. The room temperature was determined at a point adjacent to the tank unit and $53 \mathrm{in}$. above the floor by a thermocouple and by a thermometer. Temperatures relating to the tank unit were determined at five points by thermocouples: (1) the inlet thermometer, (2) the outlet thermometer, (3) the water in the main tank (which water was constantly but gently stirred by an electrically driven device, in addition to the mixing engendered by the movement of the several meters), (4) the air under the tank cover, adjacent to the heatabsorbing air meter, and (5) the products of combustion as they left the burner assembly. The cold junctions of all thermocouples were kept in an ice bath.

The procedure used in conducting tests was, first, to establish a desired equilibrium room and water temperature. Next, the condition of the calorimeter and the recorder was checked to make certain that all parts were in proper mechanical adjustment. Special care was exercised to insure such things as constant inlet gas pressure, uncontaminated room air, cleanliness of orifices and burner parts and slide wires, proper burner assembly and freedom from leaks, proper overflow of water at the weir, proper air-gas ratio, agreement of recorder scale and chart, correct mechanical balance, cold balance, etc. [4].

Temperature readings at all listed points were recorded at the beginning and end of each testing operation, with frequent observations in between, in order to evaluate the recorder reading in terms of the possible temperature factors affecting it. For example, a series of readings was taken just before the actual calibration procedures were begun, to insure that equilibrium temperature prevailed, the temperatures were then watched during the warmup period of the calorimeter until the maximum change in recorded heating value of that particular test was reached. At the conclusion of the test all temperature readings were again recorded.

Because of the over-all purpose of this study, it was agreed that it would be essential to use for calibration and testing purposes a gas with a heating value in the range of the usual natural gases, and that the heating value of such a gas should be known to a degree of accuracy at least one order of magnitude greater than that expected from the calorimeter itself. The advantages of such a gas would be: (a) its chemical and physical properties approximate those of the natural gases usually tested by the calorimeter; (b) its use would not modify the normal operation of the instrument, i. e., it could be introduced into the calorimeter without the need of changing its gears and varying the speed of rotation of the gas meter, ${ }^{4}$ without disturbing the level of the water at the weir, with the least chance of introducing an error due to contamination of the calibrating gas with constituents of fuel gas dissolved in the water in the gas meter, and without changing the bleeder burner or influencing temperatures under the tank cover; (c) it would serve as a check on the suitability of hydrogen as a calibrating gas, because hydrogen does not have the advantages listed under (a) and (b).

\section{Preparation of a Standard Gas of High Heating Value}

Because methane is the chief constituent of natural gas, a pure methane would be an ideal gas for use as a standard. A supply of natural gas consisting of nearly pure methane, and containing much smaller amounts of other constituents than the usual run of natural gas, was obtained from the Southern California Gas Co. It was hoped that an analysis of this gas by means of the mass spectrometer would make possible the calculation of the heating value with the desired accuracy. Unfortunately, because the several constituents present produced overlapping spectra which introduced too much uncertainty for an accurate calculation, it was found necessary to purify this gas further even though all of the impurities totaled less than $1 / 2$ of 1 percent. The analysis of the California gas as received was as follows:

Methane $\left(\mathrm{CH}_{4}\right.$

Percent

Ethane $\left(\mathrm{C}_{2} \mathrm{H}_{6}\right)$

Nitrogen $\left(\mathrm{N}_{2}\right)$

Propane $\left(\mathrm{C}_{3} \mathrm{H}_{8}\right)$

Propylene $\left(\mathrm{C}_{3} \mathrm{H}_{6}\right)$

Butane $\left(\mathrm{C}_{4} \mathrm{H}_{10}\right)$

Carbon dioxide $\left(\mathrm{CO}_{2}\right)$

99. 67

0. 15

04

07

02

02

03

4 The method of calibration of the calorimeter recommended by the manufac turer makes use of nearly pure hydrogen as the standard gas. Because the heating value of hydrogen is much lower than that of most fuel gases, the speed of the ing value of hydrogen is much lower than that of most fuel gases, the speed of the
gas meter is increased in the hydrogen test by appropriate changes in the gear gas meter is increased in the hydrogen test by appropriate changes in the gear
train connecting it with the driving motor so as to bring the recorder reading into train connecting it with the driving motor so as to bring the recorder reading into
the range of heating values normally met with in measurements on fue! gases. the range of heating values normally met with in measurements on fuel gases. text p. 219). 
In order to calculate the heating value of this gas, with the desired accuracy, all of the ethane and carbon dioxide should be removed, and it would be desirable also to remove the propane, propylene, and butane. In short, it was hoped to remove everything except the nitrogen, which itself would not interfere with an accurate analysis.

It is well-known that activated coconut charcoal adsorbs carbon dioxide as well as ethane and higher hydrocarbons at room temperature, and that the adsorption is improved as the pressure is increased. The apparatus that was built to utilize the adsorbing power of activated coconut charcoal is shown in figure 6 and consists of the following essential parts: Four purifying towers (A), connected in series, each with a capacity of $214 \mathrm{cu}$ in.; a manifold (B) with valves for connecting cylinders to either the inlet (I) or the outlet $(\mathrm{O})$ of the purifiers; a condenser (C) for condensing the gas by means of liquid nitrogen contained in the Dewar flask (D), which flask can be raised or lowered around the condenser by means of an adjustable platform; a vacuum pump connected to the manifold at $(\mathrm{F})$ for evacuating the entire system; and pressure gages $(\mathrm{G})$ for observing

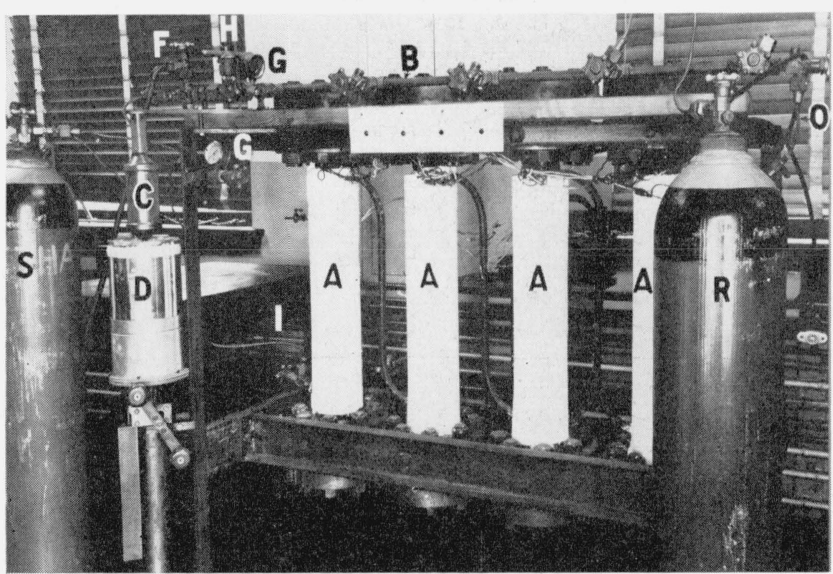

Figure 6. Apparatus for adsorbing heavy hydrocarbons.

the pressure in the system. A valve $(\mathrm{H})$ is used to divide the manifold into two parts so that the supply cylinder (S), the condenser (C), and the inlet to the purifiers can be separated from the outlet from the purifiers and the one or more receiving cylinders represented by $(\mathrm{R})$. The first purifying tower on the left is filled with a desiccant (silica gel) and the other three with activated coconut charcoal $(6$ to 8 mesh). Each tower is wrapped with a heating coil of sufficient capacity to heat the tower and its contents to a temperature of $150^{\circ} \mathrm{C}$ for the purpose of reactivation.

The whole apparatus was built so that it would withstand a hydrostatic pressure of 2,500 psi and was so tested.

Following the hydrostatic test, it was necessary to desiccate the entire apparatus thoroughly. A preliminary drying was accomplished by introducing room air for 2 days at a rate of approximately 180 cu ft/hr by means of the vacuum pump. Afterward, room air dried by a tower of silica gel was drawn through the system for 4 more days. The gel in the drying tower was changed each day and the used desiccant reactivated in an oven heated to $245^{\circ} \mathrm{C}$. During the fourth day of purging with dry air, a drying tower was also placed on the outlet of the apparatus and the amount of water picked up in each drying tower was measured. When the tower on the outlet picked up less water than the one on the inlet, it indicated that the air within the apparatus was drier than the room air. When this condition was reached, the purging with air was discontinued and the apparatus was evacuated by means of the vacuum pump until a pressure of only a few millimeters of mercury was shown on a sensitive vacuum gage connected at one of the manifold valves. Then, with the vacuum pump still operating, dry air was admitted slowly, so that the vacuum gage remained within a few millimeters of its former reading. This dry air swept out any water vapor liberated from small cracks or recesses in the interior. After several hours of this treatment the air inlet was closed, and the pump was operated until the pressure in the entire apparatus was as low as it would go, about $1 \mathrm{~mm}$ of mercury. Valve (F) was then closed, the vacuum pump turned off, and the vacuum gage read. It required a week of this procedure before the apparatus would stand evacuated overnight without any change in pressure, showing that it was both dry and vacuum-tight and was ready for use. With the apparatus still evacuated, a supply cylinder (S) of the unpurified methane was connected to the manifold, and its contents were allowed to flow at a slow rate into the purifiers through valve (I) until a pressure equilibrium was reached. The inlet valve (I) was then closed and the supply cylinder (S) was connected to the condenser (C). Gas from (S) was admitted into the condenser (C) and was condensed by cooling it slowly with liquid nitrogen. This was accomplished by gradu . ally raising the Dewar flask (D), containing the liquid nitrogen, around the condenser.

The condensing process was continued until the pressure in the supply cylinder had been reduced by $150 \mathrm{psi}$, which was the amount of change calculated to fill the condenser (C) about two-thirds full of liquid. At this point cylinder (S) was turned off and the liquid nitrogen lowered from the condenser. When, through evaporation, the pressure in the condenser had increased to the point where it at least equaled that of the gas already stored in the purifiers, the valve between the condenser and purifiers was opened and the gas from the condenser was allowed to flow into the purifiers. This continued until all of the liquid in the condenser had been vaporized, and the condenser was back up to room temperature and an equilibrium pressure prevailed.

The above process of condensing gas from the supply cylinder and transferring it to the purifiers was repeated until the pressure of gas in the purifiers had been built up to approximately 1,400 psi, which usually required three condensations. The inlet 
valve (I) was then closed and the gas allowed to remain in contact with the purifying material for approximately $12 \mathrm{hr}$ or overnight. A small sample of gas was then drawn from the outlet of the purifiers and analyzed by means of the mass spectrometer. If the results of this analysis indicated no impurities except nitrogen, the gas was allowed to flow from the purifiers into the evacuated receiving cylinder $(\mathrm{R})$ until the pressure between the two came to equilibrium.

The cycle of purification described above was repeated a sufficient number of times to bring the pressure in the receiving cylinder $(\mathrm{R})$ to at least 1,000 psi. Cylinder $\mathrm{R}$ was then removed from the system, its contents mixed by setting up convection currents within the cylinder, and the gas was then sampled and analyzed again. If this analysis showed no ethane or impurities other than nitrogen, the heating value of this purified gas was calculated from the analysis and the gas was ready for use as a standard.

Whenever a sample from the outlet $(\mathrm{O})$ of the purifiers showed a trace of ethane, indicating inefficiency of the apparatus, the process was stopped and the gas in the purifiers was condensed and returned to the supply cylinder. The heaters surrounding the purifying towers were turned on, and the system was evacuated by means of the vacuum pump. Each heating element was controlled so that a temperature of $150^{\circ} \mathrm{C}$ was maintained on each of the four towers. It was found that an overnight run was sufficient to reactivate the coconut charcoal. Reactivation proved to be necessary after every 3 or 4 purification cycles.

Four $220 \mathrm{cu} \mathrm{ft}$ cylinders of purified gas were obtained by this process, each cylinder being filled to a pressure of approximately 1,000 psi. The results of the analysis of each cylinder of gas after purifica-

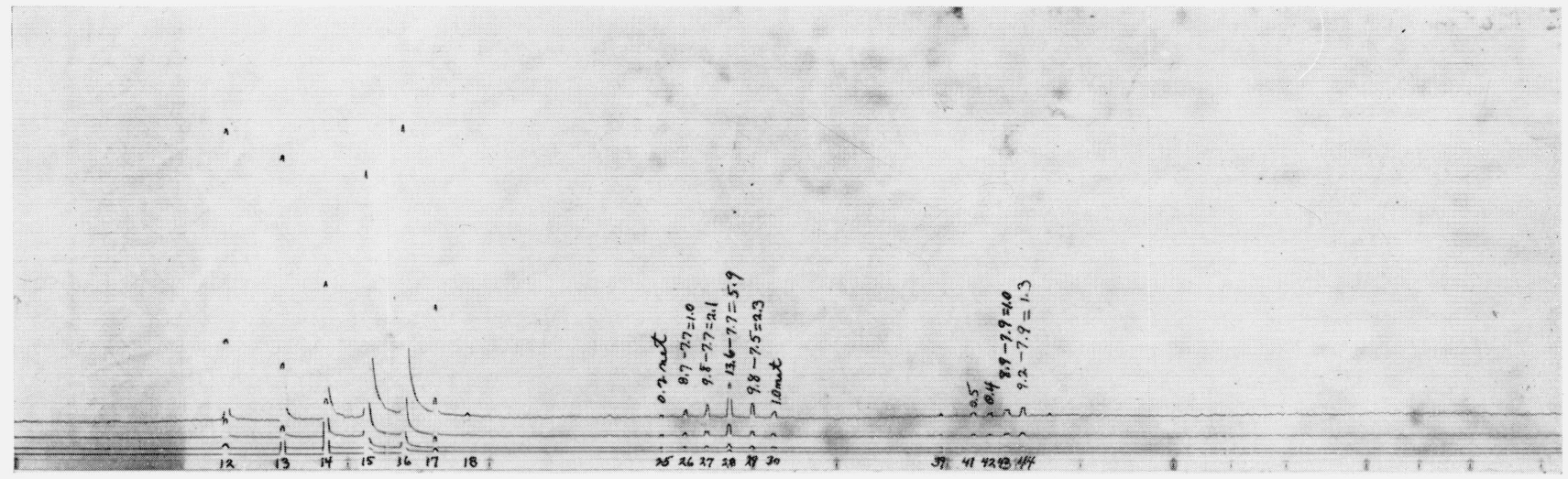

FiguRE 7. Spectrogram of natural gas before purification.

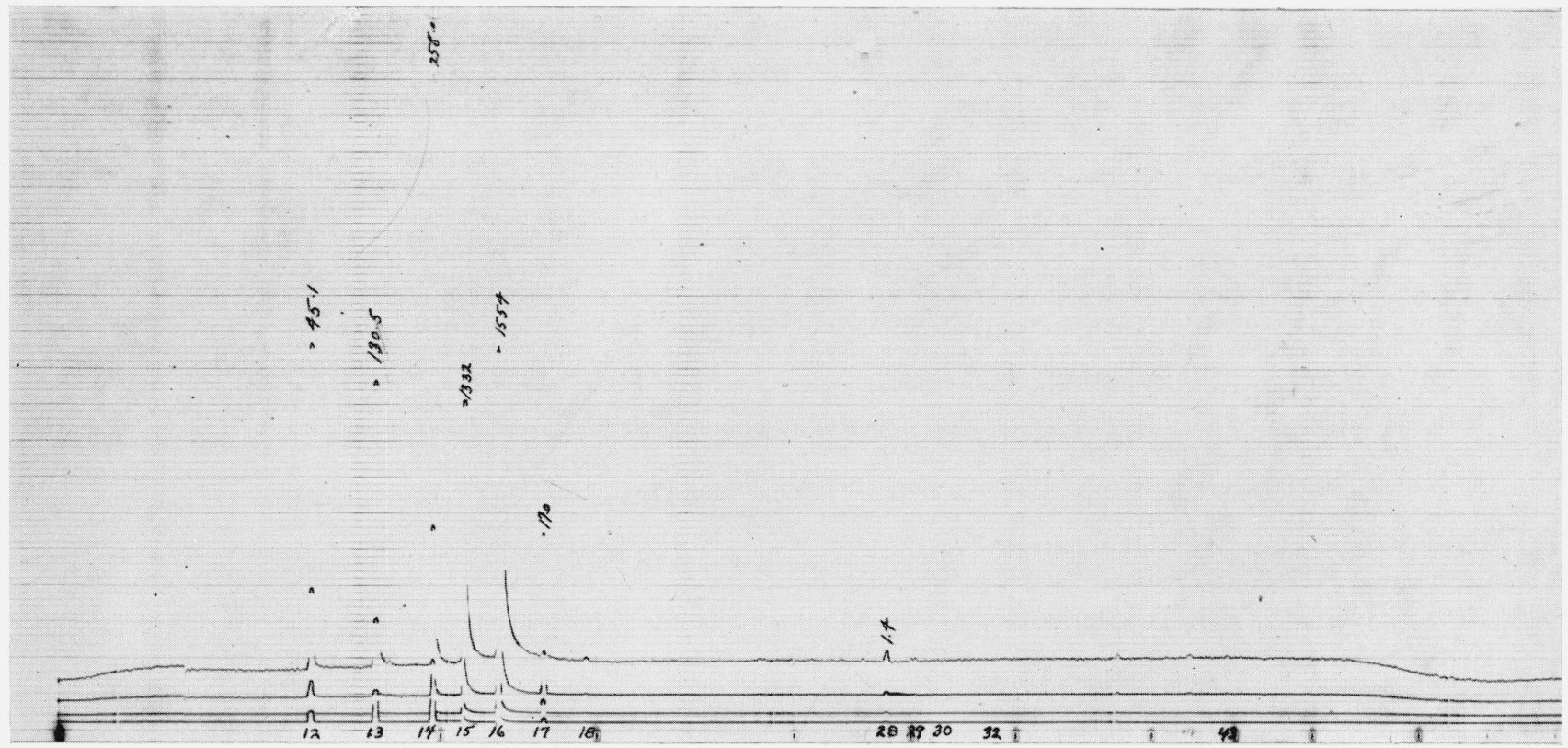

Figure 8. Spectrogram of naturai gas after purification. 
tion are shown in table $1,{ }^{5}$ together with the heating value calculated from these results. It will be seen from this table that the four samples are practically identical in composition and that the heating value from analysis is probably not more than \pm 0.1 $\mathrm{Btu} / \mathrm{cu} \mathrm{ft}$

TABLE 1. Analyses of purified methane

\begin{tabular}{|c|c|c|c|c|}
\hline \multirow{2}{*}{ Cylinder } & \multicolumn{2}{|c|}{$\begin{array}{l}\text { Analysis by mass } \\
\text { spectrometer }\end{array}$} & \multirow{2}{*}{$\begin{array}{l}\text { Calcu- } \\
\text { lated } \\
\text { heating } \\
\text { value }\end{array}$} & \multirow{2}{*}{$\begin{array}{c}\text { Probable } \\
\text { errors a }\end{array}$} \\
\hline & $\begin{array}{l}\text { Constit- } \\
\text { uent }\end{array}$ & $\begin{array}{l}\text { Mole } \\
\text { percent }\end{array}$ & & \\
\hline 127 & $\left\{\begin{array}{l}\mathrm{CH}_{4} \\
\mathrm{C}_{2} \mathrm{H}_{6} \\
\mathrm{~N}_{2}\end{array}\right.$ & $\begin{array}{r}99.93 \\
0.00 \\
.07\end{array}$ & $\begin{array}{c}\text { Btu/cu ft } \\
996.7\end{array}$ & $\begin{array}{l}\text { Btu } \\
\pm 0.1\end{array}$ \\
\hline 130 & $\left\{\begin{array}{l}\mathrm{CH}_{4} \\
\mathrm{C}_{2} \mathrm{H}_{6} \\
\mathrm{~N}_{2}\end{array}\right.$ & $\begin{array}{r}99.92 \\
0.00 \\
.08\end{array}$ & 996.6 & \pm 0.1 \\
\hline 133 & $\left\{\begin{array}{l}\mathrm{CH}_{4} \\
\mathrm{C}_{2} \mathrm{H}_{6} \\
\mathrm{~N}_{2}\end{array}\right.$ & $\begin{array}{r}99.93 \\
0.00 \\
.07\end{array}$ & 996.7 & \pm 0.1 \\
\hline 134 & $\left\{\begin{array}{l}\mathrm{CH}_{4} \\
\mathrm{C}_{2} \mathrm{H}_{6} \\
\mathrm{~N}_{2}\end{array}\right.$ & $\begin{array}{r}99.93 \\
0.00 \\
.07\end{array}$ & 996.7 & \pm 0.1 \\
\hline
\end{tabular}

a The probable errors given refer to the effect of errors in gas analysis only (see footnote 5 below).

The spectrograms from which the analyses of the California gas were calculated are shown in figures 7 and 8. Figure 7 shows the spectrogram of the gas before purification and indicates the presence of nitrogen, ethane, propylene, propane, butane, and carbon dioxide by the peaks at $28,30,42,43$, and 44. Figure 8 shows the results obtained after purification and indicates that all of the above constituents, with the exception of nitrogen, at peak 28, have been removed. This method of purification is, therefore, adequate to produce methane of sufficient purity to be analyzed with the desired precision by means of the mass spectrometer. The heating value calculated from this analysis is much more accurate than the results to be expected from the recording calorimeter. Therefore, the gas is suitable for use as a primary standard. Any stable gas of comparable heating value may be properly compared with

\footnotetext{
5 The heating values in this table were calculated on the basis that the heat of combustion of pure methane is 997.4 Btu per standard cubic foot, as given in NBS Circular C417, Gas calorimeter tables (1938). A later revision of this Circular, C464 (1948), gives 996.9 Btu per standard cubic foot. The difference in these two values is due to a difference in the definition of the Btu used in the two publications. The Btu used in C464 is defined in terms of the specific heat of water at $59^{\circ} \mathrm{F}\left(15^{\circ} \mathrm{C}\right)$ and is the unit generally used in the gas industry [2]. The use of the older value in this paper is justified by the fact that the hydrogen used in tests of the calorimeter contained about 0.06 percent of inert impurity, so that a calorimeter calibrated with hydrogen on the assumption that it is pure would read too high by 0.06 percent in the hydrogen test.

Hence a value of $996.7 \mathrm{Btu}$ on the methane of 99.93 -percent purity is subHence a value of $996.7 \mathrm{Btu}$ on the methane of 99.93-percent purity is sub-
stantially equivalent to the manufacturers recommended reading of $1,046 \mathrm{Btu}$ in a hydrogen test with hydrogen of 99.94-percent purity. It may be noted that in a hydrogen test with hydrogen of 99.94-percent purity. It may be noted that the heat of combustion of methane in terms of the International Steam Table
Btu (defined as 1,055.07 absolute joules) is $996.6 \mathrm{Btu} / \mathrm{cu} \mathrm{ft}$. The Term "cubic Btu (defined as $1,055.07$ absolute joules) is $996.6 \mathrm{Btu} / \mathrm{cu} \mathrm{ft}$. The Term "cubic
foot" as used in this paper is an abbreviation for "standard cubic foot," defined as the quantity of gas that would fill a space of $1 \mathrm{cu} \mathrm{ft}$ at $60^{\circ} \mathrm{F}$ if saturated with water vapor and under a total pressure of 30 in. of mercury.

The above values for the heat of combustion of methane are based on the experimental value per mole reported by Rossini [5], the value $0.5218 \mathrm{in}$. of mercury for the vapor pressure of water at $60^{\circ} \mathrm{F}$, and the value $(1-(p v / R T)=0.0020)$ for the deviation of methane from the ideal gas law at $60^{\circ} \mathrm{F}$ and a pressure of 30 in. of mercury. Rossini assigned an uncertainty of about 0.03 percent to his result. This corresponds to $0.3 \mathrm{Btu} / \mathrm{cu} \mathrm{ft}$. Taking account of the uncertainty in the analysis corresponding to $0.1 \mathrm{Btu} / \mathrm{cu} \mathrm{ft}$, and making some allowance for the the antainty in the deving is assigned to the beat of combustion of the purified methane.
}

this primary standard gas and may then be used as a secondary standard gas for testing or calibrating purposes (see appendix C).

\section{Comparison of Hydrogen and Methane as Calibrating Gases}

One of the questions that led to this study was the suitability of hydrogen for calibrating purposes when the calorimeter was to be used with gases having several times the heating value of the calibrating gas. The answer to this question could now be obtained by making a direct comparison between the use of hydrogen and the standard methane.

It was recognized that the use of hydrogen as a calibrating gas affects the normal operating conditions in the tank in a number of respects. For example, the use of hydrogen requires certain changes from the normal operating conditions of the instrument, including shutting off the primary air supply to the burner and the insertion of a special orifice in the gas line at the entrance to the burner. The water level surrounding the meters and the weir is disturbed when the gas meter is "blown" to refresh the water contained in the gas meter in order to facilitate a new saturation equilibrium, and when the gas meter is turning at the increased rate determined by the special hydrogen gears. Because the heat of combustion of hydrogen (approximately 319 $\mathrm{Btu} / \mathrm{cu} \mathrm{ft}$ ) is much lower than that of most fuel gases, the speed of the gas meter is increased by a definite amount in order to bring the rate of heat production and consequently the reading with hydrogen into the range of the scale used during normal operation with fuel gases. Another change is caused by the purge flame burning at its temporary down-in-the-tank location, causing temperatures under the tank cover to be different.

In comparing the two gases, the calorimeter was first proved to be in normal operating condition in accordance with the manufacturer's instructions [4]. It was then calibrated with hydrogen by the method recommended in the same instruction manual, using Hydrone hydrogen. As a part of the calibration, a small change in the cold-balance rheostat was necessary in order to make the recorder show the proper reading of 1,046 Btu on its 900 - to 1,200-Btu-range scale. ${ }^{6}$ Then, making only the necessary changes from the conditions of the hydrogen test to those of normal operation, the standard gas was connected and the chart observed until the maximum change had taken place and a steady reading was obtained,

\footnotetext{
${ }^{6}$ A table of theoretically correct readings in the hydrogen test for various ranges of the instrument is given in the manufacturer's instruction book [4] for ranges of the instrument is given in the manufacturer's instruction book [4] for use in the pertion of hydrogen together with values for the ratio of the speed of rotation of the gas meter hydrogen together with values for the ratio of the speed of rotation of the gas meter
in the hydrogen test to that in normal operation. Some allowance was also made in the hydrogen test to that in normal operation., Some allowance was also made for other effects, including the "chimney effect" discussed later in this report.
The value given in the table, which is applicable for a methane range instrument, is $1,046 \mathrm{Btu}$. The final step in the calibration referied to is an adjustment of the cold-balance rheostat $\left(\mathrm{S}_{1}\right.$, fig. 2 ) in order to bring the reading as nearly as possible to the desired value of $1,046 \mathrm{Btu}$. This procedure, rather than additional tria and error adjustments of the baffle in the burner jacket, greatly shortens the calibration time and is very effective for giving the desired calibration readin for a known gas, even though the record will be incorrect at the lower end of the scale. However, this method of adjustment does not introduce a significant ecror in comparisons readings are the gases being compared (see appendix D)
} 
as had been done for the hydrogen. The time for each evaluation averaged about $90 \mathrm{~min}$. Instead of the recorder showing the expected value of $997 \mathrm{Btu}$ for the standard gas, a reading of 1,000 was obtained, which was 3 Btu too high.

The procedure was then reversed. The instrument was calibrated with the methane to give a reading of $997 \mathrm{Btu}$ and was then checked with the hydrogen, with a resultant reading of 1,043 , or 3 Btu too low.

In order to determine whether the same results would be obtained on another calorimeter, a similar series of tests was repeated twice on a calorimeter located in the air-conditioned laboratory of the Gas Inspection Bureau of the District of Coumbia, with identical results.

It was first thought that the difference found might be caused by the type or source of the hydrogen used, but this proved not to be the case. A careful examination was made of the qualities of all of the gases involved in this problem. The composition and heating value of the methane and cylinder hydrogen used were accurately known by analysis. However, because the purity of the hydrogen generated from Hydrone had only been assumed to be sufficient not to introduce a significant error, a sample of this gas was also analyzed by means of the mass spectrometer, and the results obtained proved to be identical with the analysis obtained from the cylinder hydrogen used. The analysis is shown below:

Mole \%
Hydrogen
Oxygen
Nitrogen_._.

The question could arise as to whether all samples of hydrogen generated from different batches of Hydrone would give an analysis identical with the one listed, but it is felt that any such differences would be slight.

Additional dual tests were run, first calibrating with hydrogen and then operating with methane, with tank-water temperatures at representative equilibrium points between $60.2^{\circ}$ and $90.5^{\circ} \mathrm{F}$. In 24 such tests the results with methane differed from its known value by amounts varying from -0.3 Btu to $+4.0 \mathrm{Btu}$ and averaging $+1.68 \mathrm{Btu}$.

These differences showed no systematic variation with temperature. It may be concluded that there is a systematic difference of the order of 0.2 percent on the average between the results of calibration with hydrogen and with methane.

It seems unlikely that errors in the accepted values for the heats of combustion of methane and hydrogen could be responsible for more than a small portion of the differences found. In view of the facts that methane has physical and chemical properties approximating those of natural gas, and that calibration with methane is carried out in exactly the same manner as measurements on natural gas, it is believed that for a calorimeter to be used for measurements on natural gas, calibration with methane of accurately known composition is preferable to calibration with hydrogen.

\section{Effect of Changes in Bleeder Burner Height}

One factor which affects the performance of the Cutler-Hammer calorimeter is a so-called "chimney effect", which may be explained in principle as follows: The bleeder burner of the calorimeter is located above the water level in the tank, the effective height of the burner above water level being about $8 \frac{1}{2}$ in. Consequently the gas pressure in the inlet chamber of the gas meter will be less in experiments with hydrogen than in experiments with methane.

This difference in pressure is too small to affect the density of the gas appreciably, but it is large enough to have a significant effect on the water level in the meter, and therefore on the quantity of gas delivered by it per revolution. The effect on the calorimeter reading is approximately equal in magnitude but opposite in sign to that (discussed in reference [3]) resulting from differences between the amounts of water vapor entering and leaving the calorimeter. Both effects, and possibly others, were considered in arriving at the table of calorimeter readings for the hydrogen test [4]. If all pertinent factors were properly considered, then calibration with hydrogen and methane should yield equivalent accuracy. In view of the differences reported in the preceding section, a few experiments were performed to confirm the existence of the chimney effect and to obtain some idea of its magnitude.

The existence of differing chimney effects was proved by exaggerating the chimney height in the following manner. Two special tubes of the same inside diameter as the bleeder outlet tube, one $15 \mathrm{in}$. and the other $30 \mathrm{in}$. in length, were successively connected to the bleeder outlet tube in place of the regular bleeder burner, first, while hydrogen was being supplied to the calorimeter and again while methane was being used. It was found with the calorimeter properly calibrated and reading 1,046 Btu with the hydrogen that with the 15 -in. bleeder extension connected to the bleeder outlet tube, the chart or scale reading was $1,039.5$, or $6.5 \mathrm{Btu}$ low, and with the 30 -in. tube the reading leveled off at 1,033 , or 13 Btu low. When methane was burned under the same procedures the effects were in the same direction but of less magnitude, the drop being $2 \mathrm{Btu}$ when the 15-in. tube was used, and $4 \mathrm{Btu}$ when the 30-in. tube was used.

The chimney effect was further investigated by measuring the delivery rate of the gas meter through the means of a suitable laboratory wet-test meter, first with the calorimeter operating normally with the regular bleeder burner in place and then with the 30 -in. extension tube replacing the regular bleeder burner, while each of the respective gases was being tested. The laboratory meter was connected to the gas burner tube or outlet of the calorimeter gas meter and read when the calorimeter meter had made 10 revolutions - which was the number causing the laboratory meter most nearly to make 1 complete revolution. The average of the 10 revolutions of the calorimeter meter in each situation is shown 
in table 2. The effect on the heating value of the volumetric differences is also shown, first according to calculation and again according to the results of the "chimney-action" tests.

TABLE 2. Effect of chimney action on gas passed by calorimeter gas meter

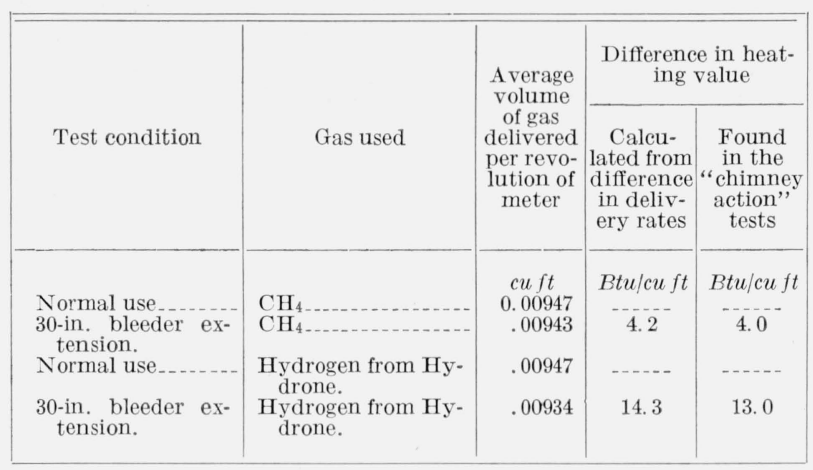

These tests confirm the existence of the chimney effect, and show that it varies with the density of the gas and with the height of the bleeder burner (see appendix E). Figure 9 shows that the effect is a linear function of the height of the bleeder burner for both hydrogen and methane.

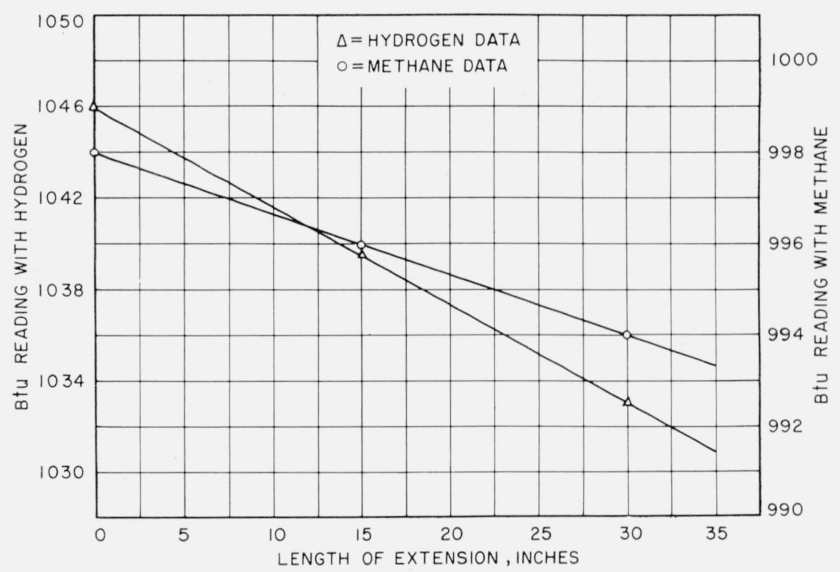

Figure 9. Effect of length of bleeder burner on Btu reading.

\section{Effect of Changes in Ambient Tempera- ture Upon the Accuracy of the Calorimeter}

Before the beginning of this study complaints had been received that changes in the termperature of the calorimeter's surroundings had an effect upon the accuracy of the instrument. Preliminary test substantiated the validity of these complaints. A complete investigation of the effects of ambient temperatures upon the instrument's accuracy was made within the operating temperatures of $50^{\circ}$ to $100^{\circ}$ F. ${ }^{7}$ In selecting these limitations it was felt

${ }^{7}$ At the factory, when calibrating the calorimeter with nearly pure hydrogen as the test gas, the manufacturer maintains the temperature of the tank water at $73^{\circ} \mathrm{F}$ and adjusts the baffle in the burner jacket (fig. 2), so as to obtain a specified reading at the recorder 0.4 percent higher than the 1,046 figure stated in the instruction manual for the methane-range instrument. The manufacturer's explanation is that the calorimeter would then be more nearly correct on the average if the temperature of the water in the tank should vary between the extremes of $60^{\circ}$ to $90^{\circ} \mathrm{F}$. that a leeway of $10 \mathrm{deg}$ beyond the $60^{\circ}$ to $90^{\circ}$ limitations advocated by the manufacturer of the calorimeter was sufficient, and also well beyond the average temperature limits of operation.

After a great deal of trial and error it was found that ordinary control of room temperatures was not sufficient for our purpose. Also, that the temperature of the water in the calorimeter cannot be assumed to be the same as that of the room, no matter how closely the temperature of the room is held to a selected figure, because of the effect of the relative humidity of the room air upon the evaporation of the tank water. Therefore, it was necessary to install adequate air-conditioning equipment for the testing room.

Using the standard methane of known heating value, the instrument was calibrated under carefully controlled conditions at a predetermined basic equilibrium temperature. After the calibration was completed and after all pertinent data had been recorded, either the room temperature was changed by $\pm 10 \mathrm{deg}$ from the current calibration or equilibrium temperature, while holding the temperature of the tank water constant, or else the room temperature was held constant and the temperature of the tank water was changed by $\pm 10 \mathrm{deg} \mathrm{F}$. During tests under each of these conditions the recorded heating value was closely observed until the maximum of any changes had been reached and remained constant following the maximum change in temperature during that particular test.

In this study, this double series of tests of plus and minus changes from selected calibration temperatures was run a number of times at each of the equilibrium temperatures of $60^{\circ}, 70^{\circ}, 80^{\circ}$, and $90^{\circ} \mathrm{F}$. For each temperature change the results in each respective plus and minus direction were practically identical. Tests of the effect of variation of room temperature showed no significant changes of recorded heating value if the water temperature remained constant. But because the water temperature does change with time and follows the room temperature, a special test was made to determine the time in which the tank water would change at least $10 \mathrm{deg}$ with a room change of $20 \mathrm{deg}$, and it was found that this could happen in approximately $10 \mathrm{hr}$. This is illustrated by figure 10 .

In table 3 are summarized the pertinent data from tests in which the tank-water temperature was changed by $10 \mathrm{deg} \mathrm{F}$ after the calibration. These figures are the average to the nearest $0.5 \mathrm{Btu}$ of the results of the several tests in each respective direction at each selected temperature.

It will be seen from table 3 , that with one exception, any change in the temperature of the tank water from the temperature at which the instrument was calibrated causes a change in the accuracy of the calorimeter that is reflected in the recorded heating value.

The magnitude of the effect on accuracy will depend upon two things, (1) the place in the temperature scale at which the temperature divergence takes place, and (2) the extent of such temperature change. 


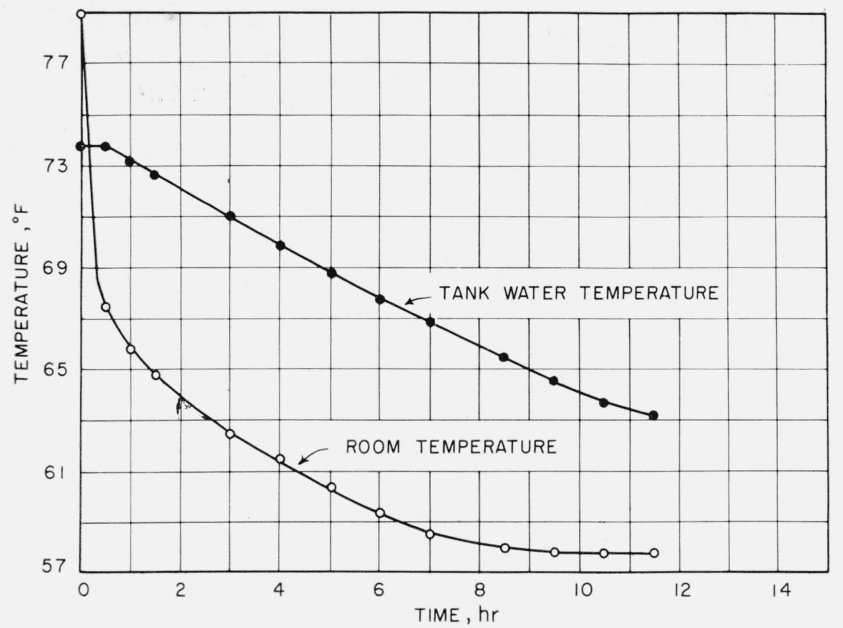

Figure 10. An example of the time required for a 20-deg $F$ change in room temperature to effect a 10-deg F change in tankwater temperature.

TABLE 3. Effect on calorimeter reading of changes in temperature of tank water

\begin{tabular}{|c|c|c|c|c|c|}
\hline Type of gas used & $\begin{array}{l}\text { Equilib- } \\
\text { rium cal- } \\
\text { ibration } \\
\text { tempera- } \\
\text { ture }\end{array}$ & $\begin{array}{l}\text { Room } \\
\text { tempera- } \\
\text { ture }\end{array}$ & $\begin{array}{l}\text { Tank } \\
\text { water } \\
\text { tempera- } \\
\text { ture }\end{array}$ & $\begin{array}{c}\text { Recorded } \\
\text { heating } \\
\text { value }\end{array}$ & $\begin{array}{c}\text { Change in } \\
\text { recorded } \\
\text { heating } \\
\text { value }\end{array}$ \\
\hline Methane (997 Btu) . & $\begin{array}{c}\circ F \\
60.0 \\
60.0 \\
60.0 \\
70.0 \\
70.0 \\
70.0 \\
80.0 \\
80.0 \\
80.0 \\
90.0 \\
90.0 \\
90.0\end{array}$ & $\begin{array}{l}\circ F \\
60.0 \\
60.0 \\
60.0 \\
70.0 \\
70.0 \\
70.0 \\
80.0 \\
80.0 \\
80.0 \\
90.0 \\
90.0 \\
90.0\end{array}$ & $\begin{array}{r}\circ F \\
60.0 \\
70.0 \\
50.0 \\
70.0 \\
80.0 \\
60.0 \\
\\
80.0 \\
90.0 \\
70.0 \\
90.0 \\
100.0 \\
80.0\end{array}$ & $\begin{array}{c}\text { Btu/cu ft } \\
997.0 \\
997.0 \\
993.5 \\
\\
997.0 \\
995.0 \\
997.0 \\
997.0 \\
989.5 \\
999.0 \\
997.0 \\
983.5 \\
1004.5\end{array}$ & $\begin{array}{c}\text { Btu/cu ft } \\
-0.0 \\
-3.5 \\
\\
-2.0 \\
0.0 \\
\\
-7.5 \\
+2.0 \\
\\
-13.5 \\
+7.5\end{array}$ \\
\hline
\end{tabular}

For example, if a 10-deg deviation occurs between $60^{\circ}$ and $70^{\circ} \mathrm{F}$, regardless of whether the instrument was calibrated at $60^{\circ}$ or $70^{\circ} \mathrm{F}$, no appreciable change in accuracy takes place. But if the instrument is calibrated at $60^{\circ} \mathrm{F}$, and the temperature of the water subsequently decreases to $50^{\circ} \mathrm{F}$, an error of 0.35 percent appears in the heating value, and it is that percentage too low. If the instrument is calibrated at $70^{\circ} \mathrm{F}$ and the temperature of the water subsequently increases to $80^{\circ} \mathrm{F}$, an error of 0.2 percent on the low side results. In the same way, if the change is from $90^{\circ}$ to $100^{\circ} \mathrm{F}$, the instrument will read low by 1.35 percent. Conversely, if the instrument is calibrated at $90^{\circ}$ and the temperature of the water subsequently changes to $80^{\circ} \mathrm{F}$, the error is in the opposite direction and the heating value reads high by 0.75 percent.

Figures 11 and 12 illustrate the effect on the heating value recorded by the calorimeter when the temperature of the water is varied both ways from the calibration temperature.

The data of table 3 may be used to plot arcurve showing the variation with temperature of the read- ing of a calorimeter calibrated to read correctly on methane at any given temperature of the water in the tank. The solid curve in figure 13 is such a curve for a calorimeter calibrated at $60^{\circ} \mathrm{F}$ (or $70^{\circ} \mathrm{F}$ ). It will be seen that the reading will be approximately correct in the range $60^{\circ}$ to $70^{\circ} \mathrm{F}$, but will be too low at temperatures below $60^{\circ}$ and above $70^{\circ}$. At $90^{\circ}$, for example, the error will be nearly 1 percent. A similar curve for a calorimeter calibrated at any other temperature, $t$, would be of the same form, but would be displaced vertically by the amount necessary to make it pass through the correct heating value $(997 \mathrm{Btu})$ at the temperature $t$. The dotted curve in figure 13 represents the reading of a calorimeter calibrated with methane to read 0.4 percent high at $73^{\circ} \mathrm{F}$ (or to read correctly at about $83^{\circ} \mathrm{F}$ ). A calorimeter thus calibrated would read high on methane by about 0.5 percent at $65^{\circ} \mathrm{F}$ and would read low by about the same amount at $90^{\circ} \mathrm{F}$. The maximum error in the range $60^{\circ}$ to $90^{\circ} \mathrm{F}$ would

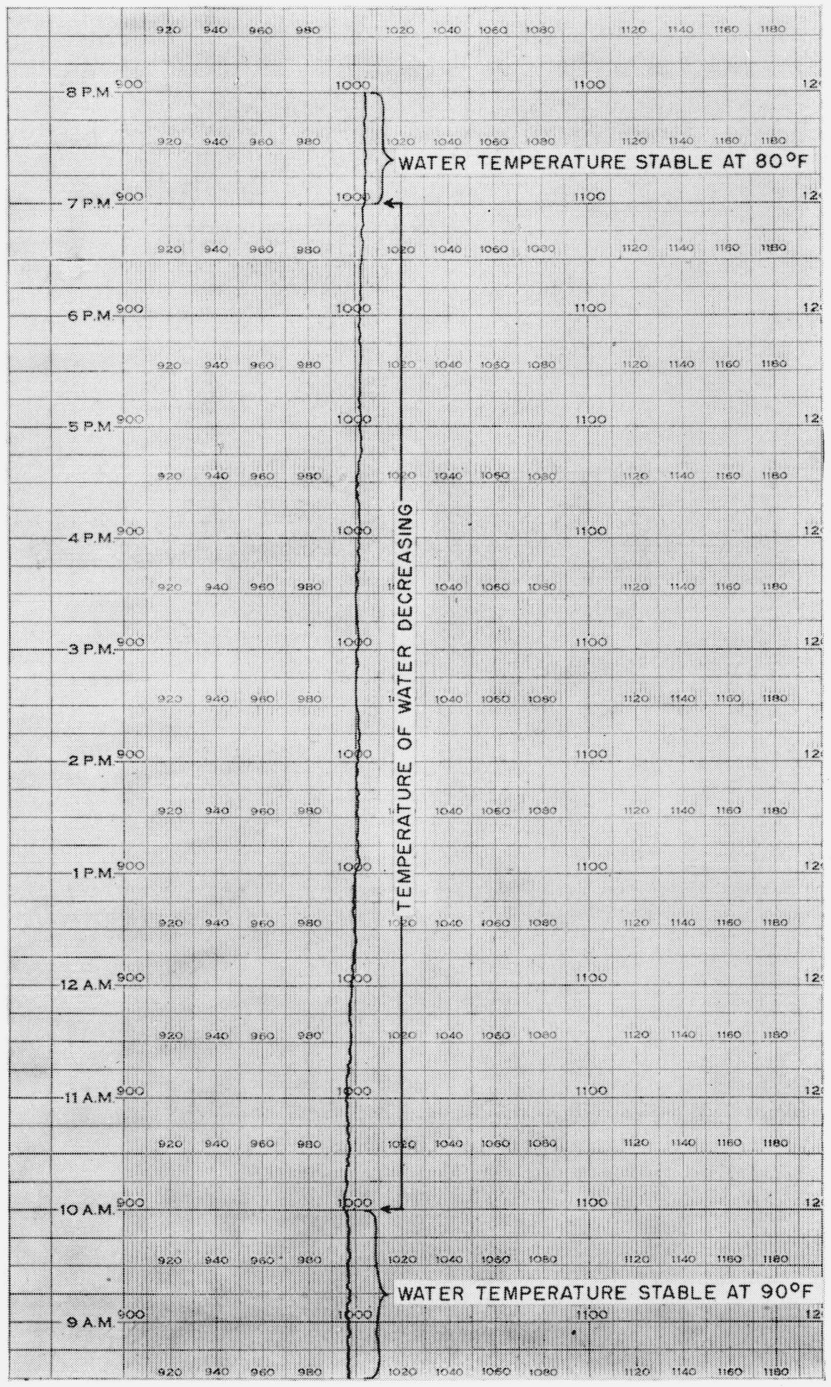

FiguRE 11. Effect of lowering tank-water temperature on Btu reading. 


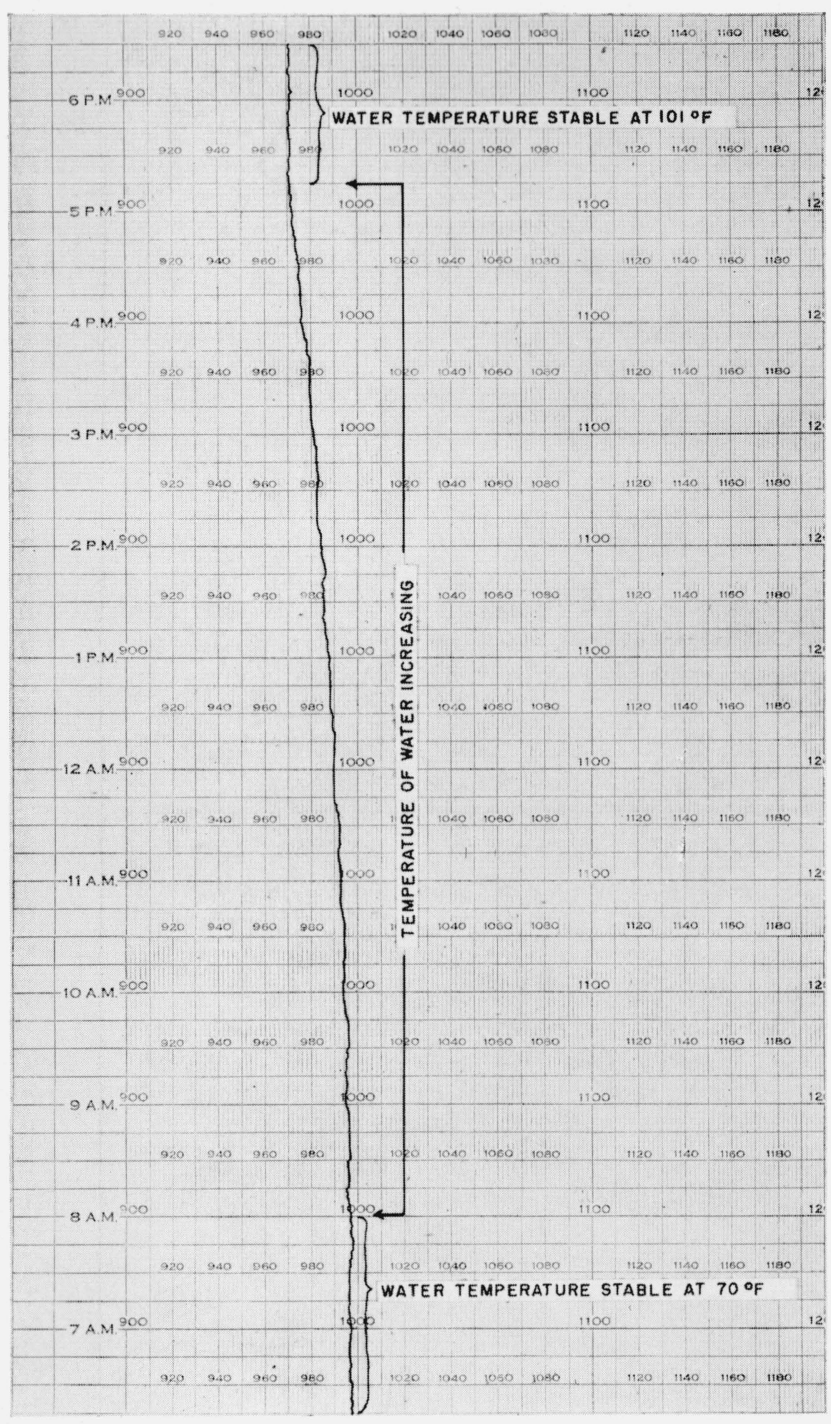

Figure 12. Effect of raising tank-water temperature on Btu reading.

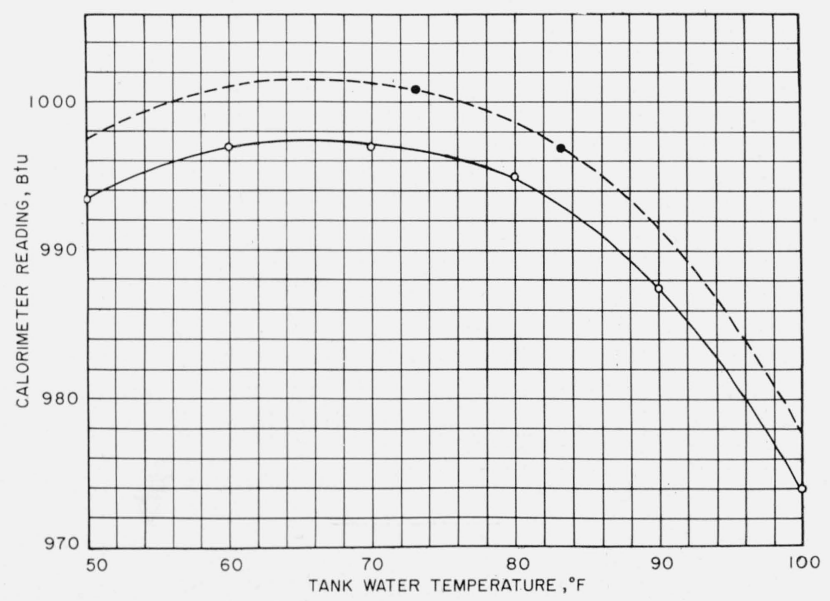

FiguRE 13. Reading of calorimeter on methane as a function of tank-water temperature. then be less than if the calorimeter had been calibrated to read correctly on methane at $73^{\circ} \mathrm{F}$, although the error in some parts of the range would be greater in the former case than in the latter. It is obvious from the results shown in table 3 and figure 13 that the temperature of the water in the calorimeter should not be allowed to go below $60^{\circ} \mathrm{F}$ or above $80^{\circ} \mathrm{F}$, if errors in recorded heating value greater than 0.2 percent from this cause alone are to be avoided. For maximum accuracy the calorimeter should be calibrated to read correctly at some convenient temperature of the water in the tank, and this temperature should be maintained constant in the subsequent use of the calorimeter.

\section{Accuracy of the Calorimeter on a Sample of Known Propane}

Because propane is being used more and more extensively in the gas industry, it was selected as a good example of one of the higher heating value gases for the purposes of our study. Accordingly, a cylinder of "instrument-grade" propane was obtained from the Phillips Petroleum Co. After analysis by the Bureau, by a combination of mass spectrometer and infrared spectrometer determinations, its heating value was calculated and found to be $2,523 \pm 3.5 \mathrm{Btu} / \mathrm{cu} \mathrm{ft}$. The results of the analysis, together with the values used for calculating the total heating value of the gas, are given in table 4.

TABLE 4. Analysis of propane sample

\begin{tabular}{|c|c|c|c|}
\hline Gas & Mole \% & ${ }^{\mathrm{a} B t u} / \mathrm{cu} \mathrm{ft}$ & $\begin{array}{c}\text { Calculated } \\
\text { Btu }\end{array}$ \\
\hline $\begin{array}{l}\text { Methane. } \\
\text { Ethane } \\
\text { Nitrogen } \\
\text { Carbon dioxide } \\
\text { Propane }\end{array}$ & $\begin{array}{r}0.15 \\
.01 \\
.07 \\
.07 \\
99.70\end{array}$ & $\begin{array}{r}996.9 \\
1758.0 \\
\hdashline 2529.0\end{array}$ & $\begin{array}{r}1.5 \\
0.2 \\
\hdashline 2521.4\end{array}$ \\
\hline & & & 2523.1 \\
\hline
\end{tabular}

aThe heating values were taken from NBS Circular 464.

As a part of the preparation for testing the propane, the following changes were made in the recorder: The standard scale, instead of the expanded scale, was made operative, and a new heatingvalue scale and chart, each graduated to 3,000 Btu were installed.

The calibration was accomplished by using the $27 \mathrm{~A}-33 \mathrm{~B}$ test gears and a cylinder of hydrogen of 99.94-percent purity at an inlet gas pressure of 0.5 in. The heating value on the recorder was adjusted for a value of 2,613 , which corrected the value shown in the Cutler-Hammer Instruction Manual [4] of 2,615 for the purity of the hydrogen used.

The tank unit was then prepared for using the propane, by the installation of the proper gears, orifices, and the "bazooka" bleeder burner. The test of the propane was made by using an inlet pressure of $0.5 \mathrm{in}$., because the bleeder burner flame tended more and more to smoke as the 0.5 -in. pressure was 
exceeded. Sufficient time was allowed to completely saturate the water in the gas meter with propane. At the conclusion of the test the recorder scale showed a heating value of $2,517 \mathrm{Btu}$, which is approximately 0.25 percent less than the value as calculated from the analysis. Judging from these results, the Cutler-Hammer calorimeter when calibrated with hydrogen can be used with reasonable accuracy for measurements on propane.

\section{Study of Effect of Inlet Gas Pressures to the Calorimeter Upon the Heating Value}

A summary was made of the inlet gas pressure (inches water column) used during all of the tests. When using hydrogen generated from Hydrone the inlet pressure varied from 0.4 to 0.7 in., as compared with 0.5 in. when using cylinder hydrogen. With methane, the inlet pressure was set at 4.5 in.,- the maximum of the $2 \frac{1 / 2}{2}$ to $4 \frac{1}{2}$ in. recommended in the instruction manual [4] for general operation.

Because the measurements on methane were made with an inlet gas pressure of 4.5 in., whereas when calibrating with hydrogen the inlet pressure averaged about 0.5 in., it was decided to determine the resulting heating value effects when, with each type of gas, the instrument was calibrated at $0.5 \mathrm{in}$. and then operated at 4.5-in. inlet pressure. A part of this series of tests (calorimeter B) was repeated on one of the instruments, previously used, in the temperature-controlled laboratory of the District of Columbia Gas Inspection Bureau (see appendix $\mathrm{F}$ for pressure tests with propane).

The results of the series of inlet pressure tests are listed in table 5 .

TABLE 5. Heating-value change when the pressure of the gas sample to the calorimeter is increased from 0.5 to 4.5 inches, water column

\begin{tabular}{|c|c|c|}
\hline \multirow{2}{*}{ Gas } & \multicolumn{2}{|c|}{ Calorimeter } \\
\cline { 2 - 3 } & A & B \\
\cline { 2 - 3 } & & \\
\cline { 2 - 3 } & Btu & Btu \\
Hydrogen ............. & +2.0 & +2.0 \\
Methane_.......... & +1.0 & +0.5 \\
\hline
\end{tabular}

\section{Conclusions}

In general, the Cutler-Hammer recording gas calorimeter when operated in accordance with the present instruction manual and at temperatures varying from $60^{\circ}$ to $90^{\circ} \mathrm{F}$ will probably give results that are accurate to within 1.0 percent.

If under the same type of care, the calorimeter is operated under controlled conditions of temperature, so that the instrument continues to operate at very close to the same temperature at which it was last calibrated, the average accuracy will probably be within 0.5 percent. However, in all considerations of temperature, the temperature of the water in the calorimeter and not the temperature of the room is to be used as the guide.
The functional accuracy of the instrument can be further improved as follows:

(a) Gas for calibration purposes should be of the same type as the gas subsequently to be sampled. Its composition must be absolutely stable, and its heating value known to a degree of accuracy at least one order of magnitude greater than the degree of accuracy expected from the calorimeter. (b) The instrument should be calibrated weekly, as a part of the weekly care, in order to determine and correct any deviations while small. (c) When possible, the inlet pressure used should be the same for both calibration and subsequent operation.

Because the Cutler-Hammer recording gas calorimeter is a self-contained instrument, a number of concurrent conditions and effects determine the accuracy at any given moment. Some of the conditions vary with the care given to the instrument by the operator and some vary with time. The accuracy is also influenced by changes accompanying operation, for example, chemical reactions in some of the burner parts cause gradual accumulations of insulating compounds that affect the absorption of heat; dust from the air tends to accumulate in the gas and air orifices and in the fins of the fluted tube; physical particles and slime tend to accumulate in the several meters; the meter bearings wear; and the surface tension characteristics of the water at the weir can change. All of these have a deleterious effect upon the efficiency of the instrument.

In the recorder, its sensitivity or response to small heating-value changes can vary because of such things as excessive tolerances of moving parts, the fineness of adjustment of the resetting levers, the degree of tension of the suspension strips, the presence of oil film or dust on the fiber pointer, imperfect contact with the slide wires, or because of a change in efficiency of the rectifier, etc. Also, variations in the humidity of the room, as well as improper tolerances in the adjustments of the rolls, can cause differences in agreement between the scale and chart amounting to as much as $2 \mathrm{Btu}$.

For any specific summation of all such effects upon the recorded heating value, the cold-balance rheostat or the baffle in the burner jacket can be changed in a direction that will cause the pen on the properiy alined chart to indicate a heating value in agreement with the heating value of the calibration gas. But, even while the calibration is in progress, or during any subsequent time interval, slight changes in some of the mentioned factors can bring about a somewhat different summation of effects. All of these effects prevent the behavior of the calorimeter from being 100-percent predictable. However, it is possible for the calorimeter to operate, under the weekly care recommended in this paper, with weekly deviations in accuracy averaging less than 0.1 per cent (see appendix $\mathrm{G}$ ).

The authors are indebted to several organizations and to many individuals connected with these organizations for valuable advice and assistance 
during the progress of this study. Acknowledgment is given to Cutler-Hammer, Inc., for furnishing a number of pieces of calorimeter equipment that were essential to this investigation, and we particularly thank E. X. Schmidt, C. W. Warner, T. M. Gilbert, and P. T. Severson of that company for helpful consultation on a number of occasions.

The Washington Gas Light Co. permitted the use of one of its calorimeters in the early part of this study and made available several pieces of test equipment, which were very useful. We express our thanks to H. L. Ketcham, Jr. who spent many hours working with us during the early part of this study, and to D. L. White for his advice and counsel.

Through the cooperation of the Rochester Gas \& Electric Corp., we obtained the services of James P. Cullen, who spent a full year on this study and contributed greatly to its successful completion.

T. L. Robey, Research Coordinator of the American Gas Association, followed the progress of this investigation and was very helpful in obtaining the support of the Association.

Careful analyses of the gas samples were essential to this study, and it was through the work of the late Martin Shepherd and that of Shuford Schuhmann, Shirley Gunther, and Fred Elder of the Gas Chemistry Section, that these were obtained.

Thanks are also due to William J. Rice for his assistance while employed by NBS.

We are indebted to the Phillips Petroleum Co. for the sample of instrument-grade propane used in this study, and we thank Guy Corfield of the Southern California Gas Co. for the supply of high-purity natural gas.

Finally, we express our appreciation to E. R. Weaver, Chief of the Gas Chemistry Section, under whose general direction this work was conducted, for his continued help and understanding.

\section{References}

[1] C. W. Waidner and E. F. Mueller, Tech. Pap. BS 4 (1914) T36.

[2] Method of test for calorific value of gaseous fuels by the water-flow calorimeter, A. S. T. M. Designation: D900 55 (1955).

[3] R. S. Jessup, The Thomas recording gas calorimeter, BS J. Research 10, 99 (1933) RP519.

[4] Cutler-Hammer Instruction Manual (Cutler-Hammer, Inc., Milwaukee, Wis., June 1950).

[5] F. D. Rossini, Heats of combustion of methane and carbon monoxide, BS J. Research 6, 37 (1931) RP260; F. D. Rossini, Heat of formation of water and heats of combustion of methane and carbon monoxide. A correction, BS J. Research 7, 329 (1931) RP343.

[6] J. H. Eiseman and Ruth F. Plapp, Weirs and the gas calorimeter, Am. Gas Assoc. Monthly 30, No. 6, (June 1948).

\section{Appendixes}

\subsection{Appendix $\bar{A}$}

During some of the comparison tests, using Hydrone hydrogen and cylinder hydrogen, some consistent differences 'in heating value seemed to appear, with the dry gas giving slightly the higher value. However, upon prolonged investigation, the apparent difference proved to be small and also questionable enough to be ignored.

\subsection{Appendix B}

A study entitled Weirs and the gas calorimeter, Am. Gas Assn. Monthly (June 1948) [6] had previously shown the crucial effect of the functioning of the weir in maintaining an exact level of the water in the calorimeter, and that accumulation of foreign material on the weir can easily cause errors in the instrument's accuracy of as much as 0.4 percent. It was also determined that a change of water level of $1.00 \mathrm{~mm}$ changes the reading by 0.7 percent. A further investigation of the effects of variations in water level was made during the current study, through the use of a slope gage $1 \mathrm{~m}$ in length. It was observed that such factors as speed of rotation of the meters, differences in the temperature of the water, changes in surface tension or any contamination at the weir, etc., all have an effect upon the level of the water. Experience in servicing calorimeters has indicated that the weir should not be touched, however, unless it is evident by observation that it is dirty or that the water is not flowing over it uniformly.

\subsection{Appendix C}

Certain precautions should be observed in using a comparison method for calibrating a gas to be employed as a secondary standard, because of the possible variations sometimes appearing in the calorimeter's results. ${ }^{8}$ The heating value found should be double-checked by an immediate additional test of the known primary gas to determine if the primary value is duplicated. The change from the one gas to the other should be accomplished through the facility of a properly designed manifold, in order that operation of the calorimeter might be continued without cessation during the changeover.

\subsection{Appendix D}

When calibrating the Cutler-Hammer calorimeter, in accordance with the present instruction manual, after all phases and parts of the various operations have been checked and properly adjusted, the final change, if necessary, to accomplish a specific reading on the recorder scale, is effected by adjustment of the baffle in the burner jacket. With some calorimeters, under certain circumstances, the amount of possible normal adjustment of this baffle is not sufficient to accomplish the desired change in scale reading. However, this can only be determined by trial and error, and much time can be spent without accomplishing the desired result. The authors found and made use of the fact that a small unbalancing of the coldbalance circuit, through arbitrary adjustment of the cold-balance rheostat produces the desired scale

8 See variations discussed on page 224 . 
reading in a minimum of time, and with no objectionable side effects upon the accuracy of the calorimeter. This was true because the arbitrary unbalancing affected the accuracy only toward the lower end of the scale, whereas all of the heating values in these experiments gave readings toward the upper end of the scale. The design of the instrument is such that when all adjustments are properly made, the coldbalance rheostat setting is approximately midway of its extremes. A difference of approximately 3 scale divisions in the rheostat setting corresponds to a change of $1 \mathrm{Btu}$ on the recorder scale, and differences up to 3 Btu can be easily and quickly compensated in this manner. That is, the position of the pen on the scale can be adjusted to read almost exactly the true heating value of the calibrating gas. However, this procedure should not be used if the gas to be sampled has a heating value that will be recorded on the chart at a point appreciably distant from that for the gas used for calibration.

\subsection{Appendix E}

When hydrogen is used as the calibrating gas, the bleeder flame is under the hood and is difficult to see. As the flame must be observed in order to properly run a test when using a hydrogen generator, some operators are known to add a 10- to 15-in. extension tube to the bleeder outlet opening during calibration, in order to bring this flame above the tank cover where it can be easily obsarved. This practice introduces an error in the calibration and causes future recordings of the calorimeter to be high.

\subsection{Appendix F}

Attempts were made to test propane at different inlet pressures, but it was found that as the pressure exceeded $0.5 \mathrm{in}$. the tendency of the bleeder flame to smoke became increasingly severe. Because of this nuisance, pressure tests using the bazooka bleeder burner were discontinued. However, it may be of interest that with an improvised bleeder burner replacing the bazooka type, consisting of a straight piece of metal tubing of the same diameter as the bleeder outlet tube and of the same height as the instrument's normal bleeder burner, pressures up to 4.5 in. could be used without an objectionable bleeder flame.
With a pressure of $4.5 \mathrm{in}$. the heating value recorded was $2,522 \mathrm{Btu}$, or very close to that calculated from the analysis, whereas, with the bazooka bleeder burner and an inlet pressure of $0.5 \mathrm{in}$., the heating value recorded was $2,517 \mathrm{Btu}$. It is realized that this change of $5.0 \mathrm{Btu}$ could be the result of a change in bleeder height along with the effect of the change in inlet pressure, because the position of the bleeder flame when the bazooka burner was used was 11 in. below the flame of the improvised bleeder burner.

\subsection{Appendix G}

An approximate 4-year record of three late model Cutler-Hammer calorimeters maintained by the Gas Inspection Bureau of the District of Columbia, operating on 1,020- to 1,200-Btu gas, shows the average weekly deviation in accuracy, as determined

TABLE 6. Approximate 4-year record of weekly deviations in accuracy of three Cutler-Hammer calorimeters, as determined by weekly checkups

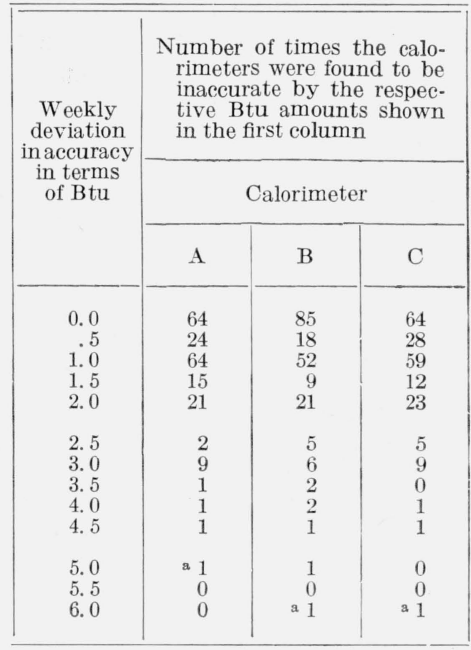

a Relates to maximum deviation found.

by weekly comparisons with a standard methanetype calibrating gas, to have been $0.93,0.88$, and $0.94 \mathrm{Btu}$, respectively (see table 6).

Washington, August 17, 1956. 